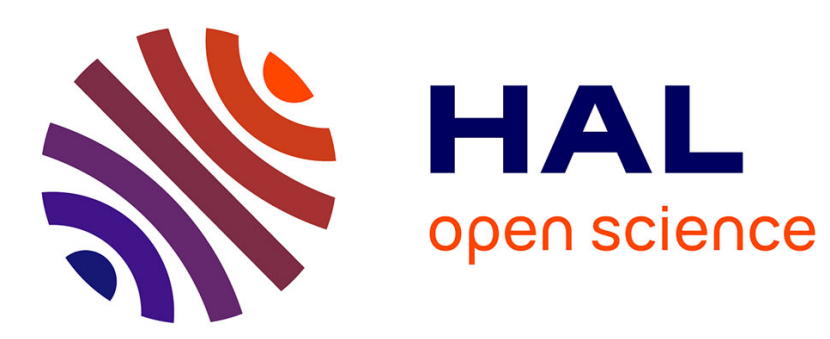

\title{
Perturbation of earthquake probability for interacting faults by static Coulomb stress changes
}

\author{
R. Console, M. Murru, G. Falcone
}

\section{To cite this version:}

R. Console, M. Murru, G. Falcone. Perturbation of earthquake probability for interacting faults by static Coulomb stress changes. Journal of Seismology, 2009, 14 (1), pp.67-77. 10.1007/s10950-0089149-4 . hal-00535489

\author{
HAL Id: hal-00535489 \\ https://hal.science/hal-00535489
}

Submitted on 11 Nov 2010

HAL is a multi-disciplinary open access archive for the deposit and dissemination of scientific research documents, whether they are published or not. The documents may come from teaching and research institutions in France or abroad, or from public or private research centers.
L'archive ouverte pluridisciplinaire HAL, est destinée au dépôt et à la diffusion de documents scientifiques de niveau recherche, publiés ou non, émanant des établissements d'enseignement et de recherche français ou étrangers, des laboratoires publics ou privés. 


\title{
Perturbation of earthquake probability for interacting faults by static Coulomb stress changes
}

\author{
R. Console • M. Murru • G. Falcone
}

Received: 22 November 2007 / Accepted: 23 December 2008 / Published online: 28 February 2009

(C) Springer Science + Business Media B.V. 2009

\begin{abstract}
This work aims at the assessment of the occurrence probability of future earthquakes on the Italian territory, conditional to the time elapsed since the last characteristic earthquake on a fault and to the history of the following events on the neighbouring active sources. We start from the estimate of the probability of occurrence in the period 2007-2036 for a characteristic earthquake on geological sources, based on a timedependent renewal model, released in the frame of Project DPC-INGV S2 (2004-2007) “Assessing the seismogenic potential and the probability of strong earthquakes in Italy". The occurrence rate of a characteristic earthquake is calculated, taking into account both permanent (clock advance) and temporary (rate-and-state) perturbations. The analysis has been carried out on a wide area of Central and Southern Italy, containing
\end{abstract}

Electronic supplementary material The online version of this article (doi:10.1007/s10950-008-9149-4) contains supplementary material, which is available to authorized users.

R. Console · M. Murru ( $\varangle)$ · G. Falcone

Istituto Nazionale di Geofisica e Vulcanologia,

Rome, Italy

e-mail: murru@ingv.it

G. Falcone

Dipartimento di Scienze della Terra,

Messina University, Messina, Italy
32 seismogenetic sources reported in the DISS 3.0.2 database. The results show that the estimated effect of earthquake interaction in this region is small if compared with the uncertainties affecting the statistical model used for the basic timedependent hazard assessment.

Keywords Static Coulomb stress changes in Italy $\cdot$ Brownian passage time $\cdot$ Rate-and-state Assessment of the occurrence probability of future shocks in Italy

\section{Introduction}

In recent years, many models for earthquake recurrence were proposed. The methodology adopted in this study is based on the fusion of the statistical renewal model called Brownian passage time (BPT, Matthews et al. 2002) with a physical model. The latter computes the instantaneous change of the static Coulomb stress $(\triangle \mathrm{CFF})$ for the computation of both the permanent and the transient effects of earthquakes occurring on the surrounding sources. The transient effects derive from the rate-and-state model for earthquake nucleation (Dieterich 1994).

According to the methodology developed in the last decade (Stein et al. 1997; Toda et al. 1998; Parsons 2004) and applied by Console et al. (2008), the probability of the next characteristic 
earthquake on a known seismogenic structure in a future time interval starts from the estimate of its occurrence rate, conditioned to the time elapsed since the previous event. To do it, two parameters are necessary: the expected mean recurrence time and the aperiodicity of the renewal process (Mc Cann et al. 1979; Shimazaki and Nakata 1980). Then, a physical model for the Coulomb stress change caused by previous earthquakes on this structure is applied. The influence of this stress change is computed by the introduction of a permanent shift on the time elapsed since the previous earthquake (clock advance or delay) or by a modification of the expected mean recurrence time.

The analysis has been carried out on a wide area of Central and Southern Italy $\left(40-43^{\circ} \mathrm{N} ; 12\right.$ $17^{\circ} \mathrm{E}$ ), containing 32 seismogenetic sources reported in the DISS 3.0.2 database (DISS Working Group 2006; Basili et al. 2008).

The area is dominated by a fairly uniform extensional regime with a sub-horizontal $\sigma_{3}$-axis normal to the Apenninic trend (i.e. SW-NE direction). Most of the sources exhibit a normal focal mechanism characterised by NW-SE strike, but we can also observe right-lateral strike-slip faults with almost pure E-W trend.

\subsection{Earthquake occurrence probability model adopted}

A procedure for seismic hazard assessment assumes that all the larger earthquakes occur on known faults for which the mechanism and the size of the characteristic event is given. The process requires the adoption of a probability density function $f(t)$ for the inter-event time between consecutive events on each fault and some basic parameters of the model. Time-independent Poisson model and renewal model based on the knowledge of the last event are the approaches most widely used in literature. The time-independent Poisson model uses an exponential function to model the occurrence of earthquakes, and only one parameter, i.e. the mean recurrence time, is required. The renewal model is the simplest representation of the non-stationarity on seismogenetic processes, and several distribution functions such as BPT, double exponential, gamma, lognormal and Weibull have been applied.

In the lack of observational evidences, in this study, we adopt the BPT distribution (Matthews et al. 2002) to represent the inter-event time probability distribution for earthquakes on individual sources. Unlike all the other renewal models, which are based only on an arbitrary choice of the probability density distribution, the BPT is associated to considerations on the fault physical properties (Zöller and Hainzl 2007). For this model, in addition to the expected mean recurrence time, $T_{\mathrm{r}}$, the coefficient of variation (also known as aperiodicity) $\alpha$ of the inter-event times is required. When $\alpha>1$, the time series exhibits clustering properties. Values below the unit indicate the possible presence of periodicity, with increasing regularity for decreasing $\alpha$.

This distribution function is expressed as:

$f\left(t ; T_{\mathrm{r}}, \alpha\right)=\left(\frac{T_{\mathrm{r}}}{2 \pi \alpha^{2} t^{3}}\right)^{1 / 2} \exp \left\{-\frac{\left(t-T_{\mathrm{r}}\right)^{2}}{2 T_{\mathrm{r}} \alpha^{2} t}\right\}$

In this study, we manipulate $f(t)$ by discretised numerical integration.

Given the probability density function and the time of the last event, we may obtain the hazard function $h(t)$ under the condition that no other event has occurred during the elapsed time $t$ (i.e. since the occurrence of the last characteristic event) by the following equation:

$h(t)=\frac{f(t)}{S(t)}=\frac{f(t)}{1-F(t)}$

where $S(t)$ is the survival function and $F(t)$ is the cumulative density function.

The hazard function allows the computation of the probability that an event occurs between time $t$ and $t+\Delta t$ :

$$
\begin{aligned}
\operatorname{Pr}[t<T \leq t+\Delta t \mid T>t] & =\frac{\operatorname{Pr}[t<T \leq t+\Delta t]}{\operatorname{Pr}[t<T]} \\
& =\frac{\int_{t}^{t+\Delta t} f(u) d u}{S(t)}
\end{aligned}
$$

This renewal process assumes that the occurrence of a characteristic event is independent of any external perturbation.

In real circumstances, earthquake sources may interact so that earthquake probability may be 
either increased or decreased with respect to what is expected by a simple renewal model. We consider fault interaction by the computation of the Coulomb static stress change or the Coulomb failure function $(\triangle \mathrm{CFF})$ caused by previous earthquakes on the investigated fault (King et al. 1994) by:

$\Delta \mathrm{CFF}=\Delta \tau+\mu^{\prime} \Delta \sigma_{\mathrm{n}}$,

where $\Delta \tau$ is the shear stress change on a given fault plane (positive in the direction of fault slip), $\Delta \sigma_{n}$ is the fault-normal stress change (positive when unclamped), and $\mu^{\prime}$ is the effective coefficient of friction.

The algorithm for $\triangle \mathrm{CFF}$ calculation assumes an Earth model such as a half space characterised by uniform elastic properties. Fault parameters like strike, dip, rake, dimensions, and average slip are necessary for all the triggering sources. Fault mechanism is also needed for the triggered source (receiver fault) in order to resolve the stress tensor on it. As we are dealing mainly with pre-instrumental events, for which details as fault shape and slip heterogeneity are not known, we assume rectangular faults with uniform stress shop distribution.

The results of such computations show that $\triangle \mathrm{CFF}$ is strongly variable in space. As discussed by Parsons (2005), the nucleation point of future earthquakes is unknown. We do not know how the tectonic stress is distributed and often have no information about asperities. What is typically known in advance is that the next earthquake is expected to nucleate somewhere along the fault plane. The $\triangle \mathrm{CFF}$ is computed as the average between the minimum and maximum depth on the specific fault.

In this study, we consider that the nucleation will occur where the $\triangle \mathrm{CFF}$ has its maximum value on the horizontal projection of the triggered fault. The effect of Coulomb static stress changes on the probability of an impending characteristic event can be approached from two points of view (Stein et al. 1997). The first idea is that the stress change can be equivalent to a modification of the expected mean recurrence time, $T_{\mathrm{r}}$, given as:

$T_{\mathrm{r}}^{\prime}=T_{\mathrm{r}}-\frac{\Delta \mathrm{CFF}}{\dot{\tau}}$ where $\dot{\tau}$ is the tectonic stressing rate. Alternatively, the time elapsed since the previous earthquake should be modified from $t$ to $t^{\prime}$ by a shift proportional to $\triangle \mathrm{CFF}$, that is:

$t^{\prime}=t+\frac{\Delta \mathrm{CFF}}{\dot{\tau}}$

According to Stein et al. (1997), both methods yield similar results. In our applications, the alternative between the first and the second view has been decided, in favour of the second one, as explained in Section 3.

Equations 5 and 6 express what has been called "permanent effect" of the stress change by Stein et al. (1997). Then, we need to consider the socalled transient effect, due to rheological properties of the slipping faults. The application of the Dieterich (1994) constitutive friction law to an infinite population of faults leads to the expression of the seismicity rate as a function of time after a sudden stress change:

$R(t)=\frac{R_{0}}{\left[\exp \left(\frac{-\Delta C F F}{A \sigma}\right)-1\right] \exp \left(\frac{t}{t_{\mathrm{a}}}\right)+1}$

where $R_{0}$ is the seismicity rate before the stress change, $A$ is a dimensionless fault constitutive parameter, $\sigma$ is the normal stress acting on the fault, $t_{\mathrm{a}}$ is a time constant (corresponding to the time at which the rate returns back to the background value) equal to $A \sigma / \dot{\tau}$, and $\dot{\tau}$ is the tectonic stressing rate (supposed unchanged by the stress step). The values of this latter parameter have been obtained for each source as explained later in Section 3.

In all our applications of Eq. 7, the $A \sigma$ free parameter of the model works as a single parameter. Its value can be determined by experimental observations on real seismicity rather than being derived from assumptions on $A$ and $\sigma$ separately. In this study, we considered $A \sigma=0.02 \mathrm{Mpa}$, a value obtained by a maximum-likelihood best fit of the free parameters of the model applied on a previous unpublished analysis of the Italian seismicity. The time-dependent rate $R(t)$ goes to zero when time goes to infinity.

We apply Eq. 7 to individual faults, with the substitution of the instantaneous value of the 
conditional occurrence rate in place of the constant background rate $R_{0}$. The assumption of a constant occurrence rate, although the conditional probability obtained for the BPT increases with elapsed time, is justified by the fact that the conditional occurrence rate changes more slowly than $R(t)$ because the time constant $T_{\mathrm{r}}$ (typically hundreds to thousands of years) is much larger than $t_{\mathrm{a}}$ (typically few years; Stein et al. 1997).

Once the time-dependent rate $R(t)$ is estimated by Eq. 7, the expected number of events $N$ over a given time interval $(t, t+\Delta t)$ is computed by integration:

$N=\int_{t}^{t+\Delta t} R(t) d t$

Under the hypothesis of a generalised Poisson process, we may finally estimate the probability of occurrence for the earthquake in the given time interval:

$P=1-\exp (-N)$

\section{Data and results}

In this study, we consider a wide region of the Apennines, limited by the rectangle of coordinates $40-43^{\circ} \mathrm{N}$ and $13-17^{\circ} \mathrm{E}$ (Fig. 1). The implementation of the method outlined in the previous section requires quantitative information about the seismogenetic faults that may interact among each other, such as the hypocentral coordinates, the expected magnitude, the focal mechanism, the fault size, the average slip, the mean recurrence time, and the date of the last event. For this purpose, we used the most comprehensive compilation of information available about Italian seismogenic sources: the Database of Individual Seismogenic Sources (DISS) owned by Istituto Nazionale di Geofisica e Vulcanologia (DISS Working Group 2006; Basili et al. 2008). Table 1 shows, for the 32 sources examined in this study, besides the code and name of the sources, some of the above-cited quantitative information, as reported in the DISS 3.0.2 database or supplied by other investigators during the project. Some sources in the investigated area have been discarded, as they lack the date of
Fig. 1 Map of the area in analysis, including both 32 seismogenetic sources (database DISS 3.0.2, September 2006) on which the probability computation is done (labelled in black) and 12 seismogenetic ones added for the $\triangle C F F$ computation in used in this study (labelled in grey without star). The sources indicated with a star have not been used in the analysis

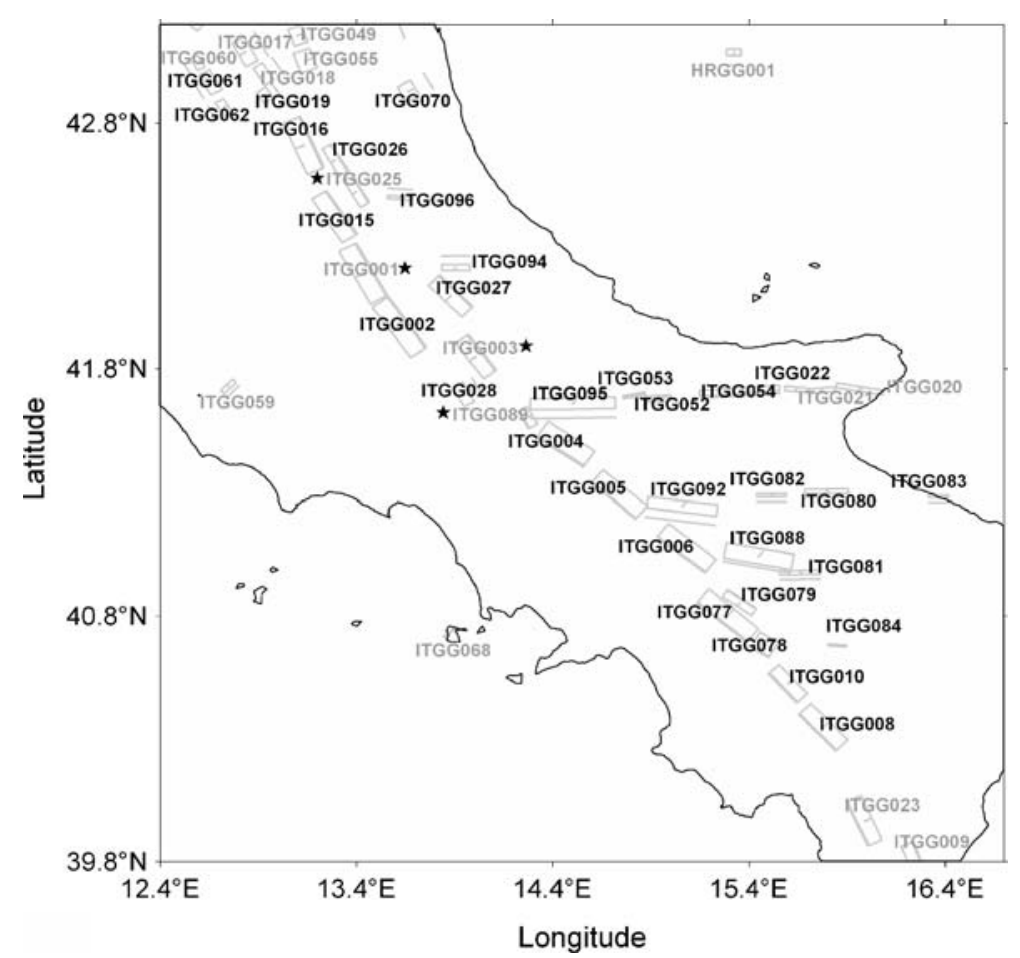


Table 1 Parameters of the seismogenetic sources considered in this study: data coming from DISS 3.02, except the last columns (Peruzza 2007)

\begin{tabular}{|c|c|c|c|c|c|c|c|c|}
\hline GG & GG name & Last event & $\mathrm{M}$ & Strike & Dip & Rake & $T_{\mathrm{rmin}} / T_{\mathrm{rmax}}$ Diss & $T_{\mathrm{r}} / \mathrm{alpha}$ \\
\hline ITGG002 & Fucino Basin & $13 / 1 / 1915$ & 6.7 & 145 & 60 & 270 & $1,400 / 2,600$ & $563 / 0.21$ \\
\hline ITGG004 & Boiano Basin & $26 / 7 / 1805$ & 6.6 & 304 & 55 & 270 & $970 / 9,700$ & $1,333 / 0.23$ \\
\hline ITGG005 & Tammaro Basin & $6 / 5 / 1688$ & 6.6 & 311 & 60 & 270 & $900 / 9,000$ & $1,317 / 0.17$ \\
\hline ITGG006 & Ufita Valley & 29/11/1732 & 6.6 & 308 & 60 & 270 & $840 / 8,400$ & $1,308 / 0.13$ \\
\hline ITGG008 & Agri Valley & $16 / 12 / 1857$ & 6.5 & 316 & 60 & 270 & $740 / 7,400$ & $1,172 / 0.11$ \\
\hline ITGG010 & Melandro-Pergola & $16 / 12 / 1857$ & 6.5 & 317 & 60 & 270 & $570 / 5,700$ & $940 / 0.07$ \\
\hline ITGG015 & Montereale Basin & $2 / 2 / 1703$ & 6.5 & 147 & 60 & 270 & $720 / 7,200$ & $1,170 / 0.1$ \\
\hline ITGG016 & Norcia Basin & $14 / 1 / 1703$ & 6.5 & 157 & 60 & 270 & $2,000 / 10,000$ & $1,830 / 0.1$ \\
\hline ITGG019 & Sellano & 14/10/1997 & 5.6 & 144 & 40 & 260 & $700 / 2,100$ & $410 / 0.19$ \\
\hline ITGG022 & San Marco Lamis & $6 / 12 / 1875$ & 6.1 & 95 & 80 & 215 & $700 / 4,800$ & $665 / 0.36$ \\
\hline ITGG026 & Amatrice & 7/10/1639 & 6.1 & 150 & 65 & 270 & $1,075 / 1,954$ & $1,319 / 0.04$ \\
\hline ITGG027 & Sulmona Basin & 3/12/1315 & 6.4 & 135 & 60 & 270 & $942 / 1,100$ & $888 / 0.1$ \\
\hline ITGG028 & Barrea & $7 / 5 / 1984$ & 5.8 & 152 & 50 & 264 & $700 / 2,700$ & $523 / 0.1$ \\
\hline ITGG052 & San Giuliano di Puglia & $31 / 10 / 2002$ & 5.8 & 267 & 82 & 203 & $700 / 2,000$ & $498 / 0.25$ \\
\hline ITGG053 & Ripabottoni & $1 / 11 / 2002$ & 5.7 & 261 & 86 & 195 & $700 / 1,800$ & $442 / 0.29$ \\
\hline ITGG054 & San Severo & $30 / 7 / 1627$ & 6.8 & 266 & 80 & 215 & $900 / 9,000$ & $1,687 / 0.22$ \\
\hline ITGG061 & Foligno & $13 / 1 / 1832$ & 5.8 & 330 & 30 & 270 & $700 / 3,500$ & $598 / 0.19$ \\
\hline ITGG062 & Trevi & $15 / 9 / 1878$ & 5.5 & 330 & 30 & 270 & $700 / 2,500$ & $436 / 0.26$ \\
\hline ITGG070 & Offida & 3/10/1943 & 5.9 & 150 & 35 & 90 & $700 / 4,000$ & $701 / 0.25$ \\
\hline ITGG077 & Colliano & 23/11/1980 & 6.8 & 310 & 60 & 270 & $1,680 / 3,140$ & $1,971 / 0.44$ \\
\hline ITGG078 & San Gregorio Magno & 23/11/1980 & 6.2 & 300 & 60 & 270 & $1,680 / 3,140$ & $825 / 0.54$ \\
\hline ITGG079 & Pescopagano & 23/11/1980 & 6.2 & 124 & 70 & 270 & $1,680 / 3,140$ & $914 / 0.09$ \\
\hline ITGG080 & Cerignola & $20 / 3 / 1731$ & 6.3 & 269 & 80 & 180 & $700 / 6,000$ & $959 / 0.17$ \\
\hline ITGG081 & Melfi & $14 / 8 / 1851$ & 6.3 & 269 & 80 & 180 & $700 / 6,600$ & $964 / 0.21$ \\
\hline ITGG082 & Ascoli Satriano & $17 / 7 / 1361$ & 6.0 & 269 & 80 & 180 & $700 / 4,200$ & $685 / 0.11$ \\
\hline ITGG083 & Bisceglie & $11 / 5 / 1560$ & 5.7 & 269 & 80 & 180 & $700 / 2,900$ & $490 / 0.07$ \\
\hline ITGG084 & Potenza & $5 / 5 / 1990$ & 5.7 & 95 & 88 & 175 & $700 / 2,600$ & $508 / 0.21$ \\
\hline ITGG088 & Bisaccia & 23/7/1930 & 6.7 & 280 & 64 & 237 & $950 / 9,500$ & $1,460 / 0.16$ \\
\hline ITGG092 & Ariano Irpino & $5 / 12 / 1456$ & 6.9 & 85 & 70 & 230 & $2,000 / 20,000$ & $2,082 / 0.54$ \\
\hline ITGG094 & Tocco da Casauria & $30 / 12 / 1456$ & 6.0 & 89 & 70 & 230 & $700 / 4,500$ & $699 / 0.12$ \\
\hline ITGG095 & Frosolone & $30 / 12 / 1457$ & 7.0 & 83 & 70 & 230 & $2,500 / 25,000$ & $2,469 / 0.18$ \\
\hline ITGG096 & Isola del Gran Sasso & $5 / 9 / 1950$ & 5.7 & 95 & 75 & 225 & $700 / 2,500$ & $524 / 0.26$ \\
\hline
\end{tabular}

the last event, i.e. ITGG001 (Ovindoli-Pezza), ITGG003 (Aremogna-Cinque Miglia), ITGG025 (Campotosto) and ITGG089 (Carpino-Le Piane), indicated with a star in Fig. 1; the release of the database (DISS 3.02) is the one chosen as reference model by all the teams working at S2 Project.

Considering the methodological character of this study, we accept that the sources given in the DISS release the tectonic stress mainly through characteristic earthquakes, even in lack of evidence for the validity of the characteristic earthquake model in the region under study.

We made direct use of the BPT model described by Eq. 1 with the purpose of a methodological investigation about its properties. The computation of the occurrence conditional probability of future earthquakes would require the knowledge of the mean recurrence time of characteristic earthquakes, based on historical or paleoseismological data.

In lack of historical data spanning a time interval significantly longer than the mean recurrence times on the analysed sources and given also the rareness of paleoseismological data for most of the same sources, we decided to use both the mean recurrence time $T_{\mathrm{r}}$, the aperiodicity parameter $\alpha$, and the time elapsed since the latest event for each of the 32 seismogenetic sources obtained by L. Peruzza for the INGV-DPC S2 project. These data are reported in the last column of Table 1 . 
A report on the abovementioned project has been reported in 2007 by Peruzza.

The computation of the hazard function conditional to the time elapsed since the latest characteristic earthquake has allowed the estimate of the probability of occurrence of the next possible event in a future time interval (in our case, assumed 30 years long starting on 2007). These probabilities are shown in Table 3 .

We have then analysed the variation of these probabilities by the perturbation produced on the specific individual source by the cumulative stress changes due to the co-seismic slip of all earthquakes that occurred after the latest characteristic earthquake on a certain fault segment.

Among the events that could have potentially changed the stress conditions on the studied faults, we have considered:

- The latest characteristic events associated to the same seismogenetic sources (43 earthquakes reported in DISS), including 11 earthquakes occurred in the surrounding areas;

- The events reported in the CPTI04 (2004) catalog associated to the Areal Sources (113 events with $M_{\mathrm{w}} \geq 5.0$ ) from results of Task 1 of the INGV-DPC S2 project (Fig. 2);
- The events reported in the catalog CSI (19862002, three events with $M_{1} \geq 5.0$ ) (Chiarabba et al. 2005) plus those reported in the more recent bulletins (2003-2006, two events with $\left.M_{1} \geq 5.0\right)$ (Fig. 2).

The stress change was computed for each of the 32 receiving sources (Table 1 ), using the parameters released in the DISS database (origin time of the latest event, hypocentral coordinates, focal mechanism, fault size and average slip). The earthquake mechanism is needed for both the triggering and receiver faults.

The focal mechanisms of the causative events needed for the stress change computation have been taken from the DISS database for the respective sources or inferred from the seismogenic areas to which the events not reported in the DISS database belonged.

We have computed the clock change, $\Delta t$, by the ratio between $\Delta \mathrm{CFF}$ and $\dot{\tau}$ (tectonic stress change rate). The time change is positive (the fault becomes closer to failure) if the Coulomb stress change is positive. In the opposite case (negative change), the fault becomes farther from failure, being possible, in extreme situations, that the elapsed time is reset to zero. The values of $\dot{\tau}$
Fig. 2 Map of the events considered in the analysis. The seismogenetic areas to which these events are supposed to belong are also indicated

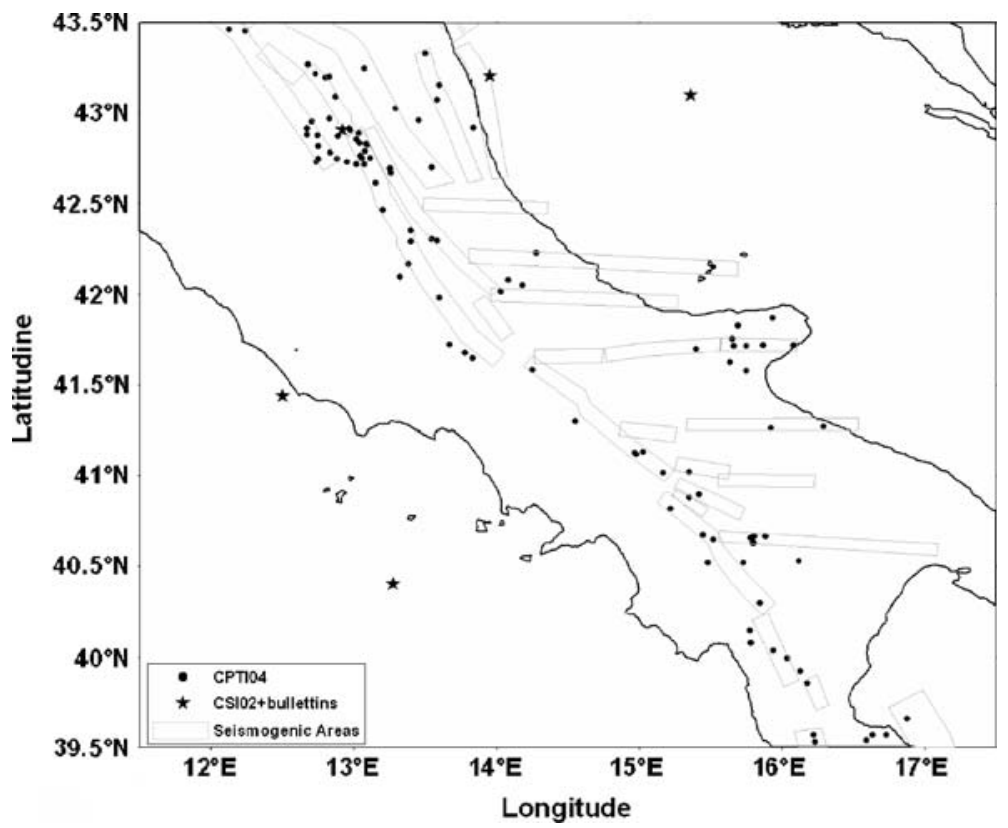


Table 2 Physical parameters used for computing the time change

\begin{tabular}{|c|c|c|c|c|}
\hline$\overline{\mathrm{GG}}$ & $\begin{array}{l}\text { Strain rate } \\
\text { (nanostrain/year) }\end{array}$ & $\begin{array}{l}\text { Tau_dot } \\
(\mathrm{Pa} / \text { year })\end{array}$ & $\triangle \mathrm{CFF}(\mathrm{MPa})$ & $\begin{array}{c}\Delta \mathrm{t}=\Delta \mathrm{CFF} / \\
\mathrm{tau} \_ \text {dot (year) }\end{array}$ \\
\hline ITGG002 & 17.0 & 412.3 & -0.4300 & -1042.9 \\
\hline ITGG004 & 22.7 & 597.3 & 0.0036 & 6.0 \\
\hline ITGG005 & 22.7 & 597.3 & 0.2300 & 385.0 \\
\hline ITGG006 & 22.7 & 597.3 & 0.2900 & 485.5 \\
\hline ITGG008 & 16.4 & 397.8 & 0.0102 & 25.6 \\
\hline ITGG010 & 16.4 & 397.8 & 0.0203 & 51.0 \\
\hline ITGG015 & 16.4 & 397.8 & 0.2046 & 514.2 \\
\hline ITGG016 & 17.0 & 412.3 & 0.6107 & 1481.1 \\
\hline ITGG019 & 42.8 & 1180.1 & 0.0001 & 0.1 \\
\hline ITGG022 & 1.2 & 33.6 & 0.0143 & 426.2 \\
\hline ITGG026 & 14.9 & 319.7 & 0.0761 & 238.1 \\
\hline ITGG027 & 14.9 & 361.4 & 0.0461 & 127.5 \\
\hline ITGG028 & 17.0 & 468.8 & 0.0003 & 0.7 \\
\hline ITGG052 & 0.9 & 25.2 & -0.0525 & -2084.9 \\
\hline ITGG053 & 0.9 & 25.2 & 0.0000 & 1.1 \\
\hline ITGG054 & 0.9 & 25.2 & 0.0261 & 1037.6 \\
\hline ITGG061 & 9.3 & 225.5 & 0.0423 & 187.4 \\
\hline ITGG062 & 9.3 & 225.5 & -0.0168 & -74.4 \\
\hline ITGG070 & 11.5 & 302.5 & 0.0031 & 10.3 \\
\hline ITGG077 & 16.4 & 397.8 & 0.0007 & 1.7 \\
\hline ITGG078 & 16.4 & 397.8 & 0.0017 & 4.2 \\
\hline ITGG079 & 35.3 & 635.7 & 0.0001 & 0.2 \\
\hline ITGG080 & 1.0 & 28.0 & -0.0797 & -2845.4 \\
\hline ITGG081 & 1.2 & 33.6 & -0.3104 & -9237.7 \\
\hline ITGG082 & 1.0 & 28.0 & -0.0359 & -1283.2 \\
\hline ITGG083 & 1.0 & 28.0 & -0.0087 & -309.3 \\
\hline ITGG084 & 6.9 & 193.2 & -0.0545 & -282.1 \\
\hline ITGG088 & 5.2 & 145.6 & -0.2529 & -1737.1 \\
\hline ITGG092 & 3.6 & 100.8 & 0.4055 & 4022.8 \\
\hline ITGG094 & 1.4 & 25.2 & 0.1044 & 4143.8 \\
\hline ITGG095 & 24.8 & 694.4 & 0.1197 & 172.4 \\
\hline ITGG096 & 3.8 & 53.3 & 0.0003 & 5.0 \\
\hline
\end{tabular}

have been computed for each source by the strain rate obtained by S. Barba for the INGV-DPC S2 project. These values of strain rate were obtained by different numerical models of deformation for Italy using a finite element method and calculating the nodal velocity by the weighted residual method through the use of the software SHELLS (Bird 1999) suitably modified to include the representation of the seismogenic Italian faults.

The strain tensor has been resolved on the specific source, taking into account the mechanism of its characteristic earthquakes. The values of the shear strain component so obtained allows the computation of $\dot{\tau}$ multiplying it by $\mu=3 \times 10^{3} \mathrm{~Pa}$.
Table 2 contains, for the 32 seismogenetic sources, the physical parameters relevant for the computation of the clock advance or delay: the strain and the stress rate obtained from geodetic observations, the stress change caused by the subsequent earthquakes and the time change $(\Delta t=$ $\Delta \mathrm{CFF} / \dot{\tau})$.

For some of the 32 sources, the clock advance was larger than the mean recurrence time of the source itself. In this case, Eq. 5 cannot be applied. Therefore, for this reason, we always use Eq. 6 for the computation of a modified larger elapsed time. On the contrary, if the clock delay is negative and its modulus is larger than the elapsed time, Eq. 6 
Table 3 Results of the statistical analysis

\begin{tabular}{|c|c|c|c|c|c|c|}
\hline$\overline{\mathrm{GG}}$ & $\begin{array}{l}\text { Elapsed } \\
\text { time (year) }\end{array}$ & $\Delta t$ (year) & $\begin{array}{l}\text { Mean recurrence } \\
\text { time (year) }\end{array}$ & $P(30)(\%)$ & P_mod(30) (\%) & $P_{-}$trans $(30)(\%)$ \\
\hline ITGG002 & 92 & -1042.9 & 562.5 & 0.0 & 0.0 & 0.0 \\
\hline ITGG004 & 202 & 6.0 & 1332.5 & 0.0 & 0.0 & 0.0 \\
\hline ITGG005 & 319 & 385.0 & 1317.1 & 0.0 & 0.0 & 0.0 \\
\hline ITGG006 & 275 & 485.5 & 1307.7 & 0.0 & 0.0 & 0.0 \\
\hline ITGG008 & 150 & 25.6 & 1171.6 & 0.0 & 0.0 & 0.0 \\
\hline ITGG010 & 150 & 51.0 & 940.4 & 0.0 & 0.0 & 0.0 \\
\hline ITGG015 & 304 & 514.2 & 1170.3 & 0.0 & 0.1 & 0.0 \\
\hline ITGG016 & 304 & 1481.1 & 1830.3 & 0.0 & 12.7 & 10.9 \\
\hline ITGG019 & 10 & 0.1 & 410.2 & 0.0 & 0.0 & 0.0 \\
\hline ITGG022 & 132 & 426.2 & 665.1 & 0.0 & 9.2 & 1.3 \\
\hline ITGG026 & 368 & 238.1 & 1318.5 & 0.0 & 0.0 & 0.0 \\
\hline ITGG027 & 692 & 127.5 & 888.1 & 1.4 & 15.6 & 12.8 \\
\hline ITGG028 & 23 & 0.7 & 523.2 & 0.0 & 0.0 & 0.0 \\
\hline ITGG052 & 5 & -2084.9 & 498.3 & 0.0 & 0.0 & 0.0 \\
\hline ITGG053 & 5 & 1.1 & 442 & 0.0 & 0.0 & 0.0 \\
\hline ITGG054 & 380 & 1037.6 & 1687.1 & 0.0 & 4.1 & 1.3 \\
\hline ITGG061 & 175 & 187.4 & 598.1 & 0.0 & 1.1 & 0.6 \\
\hline ITGG062 & 129 & -74.4 & 435.7 & 0.0 & 0.0 & 0.0 \\
\hline ITGG070 & 64 & 10.3 & 701.1 & 0.0 & 0.0 & 0.0 \\
\hline ITGG077 & 27 & 1.7 & 1970.9 & 0.0 & 0.0 & 0.0 \\
\hline ITGG078 & 27 & 4.2 & 824.6 & 0.0 & 0.0 & 0.0 \\
\hline ITGG079 & 27 & 0.2 & 914.3 & 0.0 & 0.0 & 0.0 \\
\hline ITGG080 & 276 & -2845.4 & 958.6 & 0.0 & 0.0 & 0.0 \\
\hline ITGG081 & 156 & -9237.7 & 964.3 & 0.0 & 0.0 & 0.0 \\
\hline ITGG082 & 646 & -1283.2 & 684.5 & 23.0 & 0.0 & 0.0 \\
\hline ITGG083 & 447 & -309.3 & 489.9 & 29.6 & 0.0 & 0.0 \\
\hline ITGG084 & 17 & -282.1 & 507.8 & 0.0 & 0.0 & 0.0 \\
\hline ITGG088 & 77 & -1737.1 & 1459.8 & 0.0 & 0.0 & 0.0 \\
\hline ITGG092 & 551 & 4022.8 & 2081.8 & 0.3 & 2.9 & 2.9 \\
\hline ITGG094 & 551 & 4143.8 & 698.8 & 4.1 & 0.0 & 0.0 \\
\hline ITGG095 & 551 & 172.4 & 2468.5 & 0.0 & 0.0 & 0.0 \\
\hline ITGG096 & 57 & 5.0 & 523.7 & 0.0 & 0.0 & 0.0 \\
\hline
\end{tabular}

would provide a negative modified elapsed time $t^{\prime}$. In this case, we fix $t^{\prime}=0$, as the receiving event had just occurred.

These so modified elapsed times have been used for computing new probabilities of an earthquake exceeding the threshold magnitude for the next 30 years after 1 January 2007.

As an example of how our procedure works, if we have a fault with $T_{\mathrm{r}}=1,000$ years, $t=$ 800 years, $\alpha=0.5$, Eq. 3 gives $P(30)=5.1 \%$. If we assume now a positive clock change $\Delta t=$ 400 years and $t^{\prime}=1,200 \mathrm{yr}$, the same equation gives an increased probability $P_{\bmod }(30)=6.1 \%$.

The instantaneous occurrence rates have been used in the application of the rate-and-state model by Eq. 7 for the estimate of the transient effect assuming $R_{0}=h(t)$. The probability connected to the transient effect, combined with the permanent effect, has been computed by Eqs. 8 and 9. For the application of Eq. 7, the time constant $t_{\mathrm{a}}$ has been obtained through its definition $t_{\mathrm{a}}=A \sigma / \dot{\tau}$, where $\dot{\tau}$, the tectonic stressing rate in the area, is the same as that used for the computation of the clock change on the fault.

Table 3 reports, for each of the 32 sources, the time elapsed since the last earthquake, the mean recurrence time, the conditional occurrence probability in the next 30 years, $P(30)$, the probability modified by the permanent effect of the subsequent earthquakes, $P \_\bmod (30)$, and the probability obtained from the sum of the permanent and the transient effect, P_trans(30). 


\section{Discussion}

As an example of the adopted methodology, the computation of the $\triangle \mathrm{CFF}$ on the MelandroPergola fault is shown in Fig. 3.

It is possible to note how the events subsequent to the December 13, 1857 earthquake caused on the different parts of this structure positive stress changes ranging between 0.02 and $0.2 \mathrm{MPa}$.

Failure is encouraged in the source parts where $\triangle \mathrm{CFF}$ is positive and discouraged if it is negative. The zones with a positive change will have an advance in the expected occurrence time (clock change) of the next large earthquake on the examined source. In the Electronic supplementary materials, the full set of maps representing the earthquake-after-earthquake Coulomb stress changes is given.

From Table 3, it can be noted that, for most of the sources, the renewal model forecasts a negligible probability of occurrence for the next 30 years, due to the relatively short elapsed time, compared with the mean recurrence time. On the contrary, the sources with elapsed time close to the mean recurrence time exhibit high hazard because of the high periodicity due to very small alpha values. The only two sources that exhibit a probability larger than 20\% are ITGG082 (Ascoli Satriano) and ITGG083 (Bisceglie). It is important to note that a time-independent uniform Poisson model would lead to more uniform probability estimates, ranging from $1.2 \%$ to $7.5 \%$ in 30 years, if the maximum and minimum mean recurrence times given by DISS compilers are taken.

It is interesting to note also that, for some of the sources, the stress change due to the subsequent events, producing a clock advance of several hundred years, has affected the probability of occurrence, increasing significantly its value. This happened in particular, for Norcia Basin (12.7\%), San Marco in Lamis (9.2\%), Sulmona Basin (15.6\%), San Severo (4.1\%), Foligno (1.1\%) and Ariano Irpino $(2.9 \%)$. Conversely, the relatively high probability of the two previously mentioned faults (ITGG082 and ITGG083) has dropped to zero due to the negative value of $\triangle \mathrm{CFF}$ in their area and a consequent large clock delay.

The probabilities obtained from the transient effect are generally smaller than the conditional probabilities obtained from the permanent effect only. This is due to the assumption of constant background rate made for the application of the rate-and-state model. Anyway, the transient effect decays as the supply of nucleation sites is consumed; the duration of the transient is inversely proportional to the fault stressing rate.

In Fig. 4, the expected probability values in the next 30 years, starting on January 1, 2007, have
Fig. 3 Coulomb failure change at a depth of $5.9 \mathrm{~km}$ caused by all earthquakes after December 16, 1857. The focal mechanism used in the computation for the receiver fault is assumed the same as that of the "Melandro-Pergola" earthquake. The fault plane solutions of the seismogenetic sources (red boxes) and the events of the CPTI04 that have failed after December 16, 1857 have been added

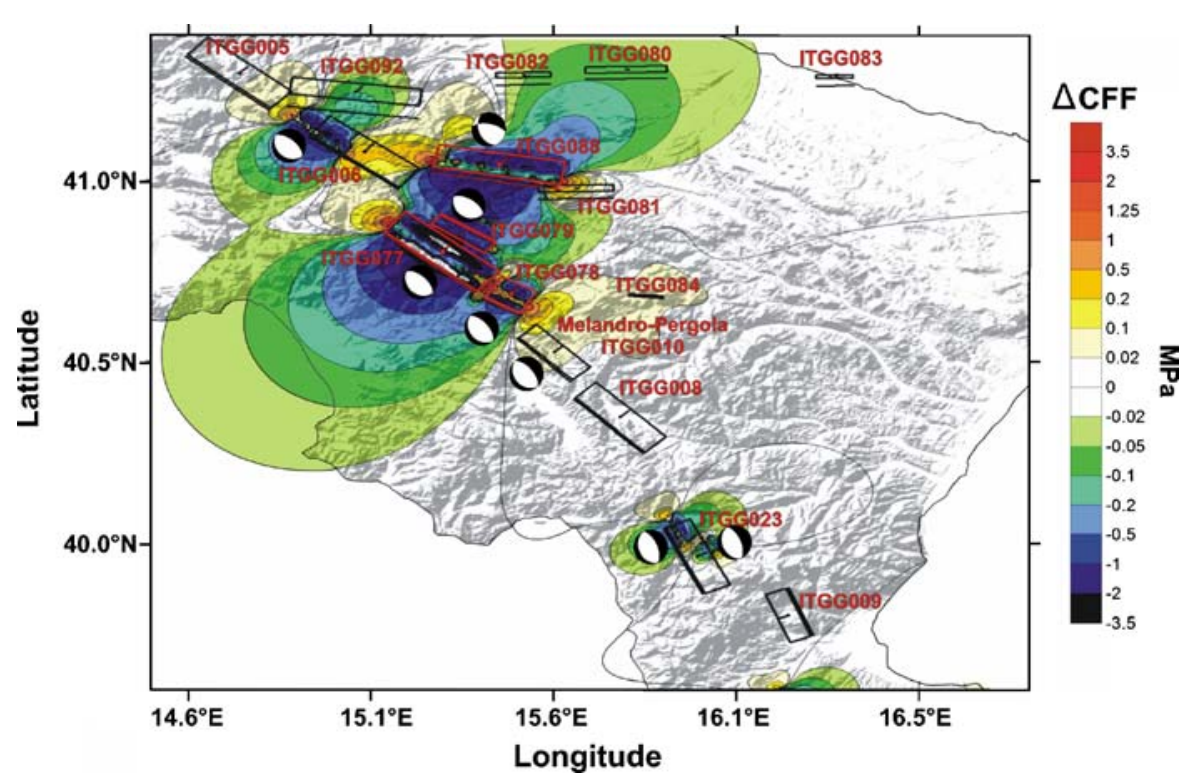




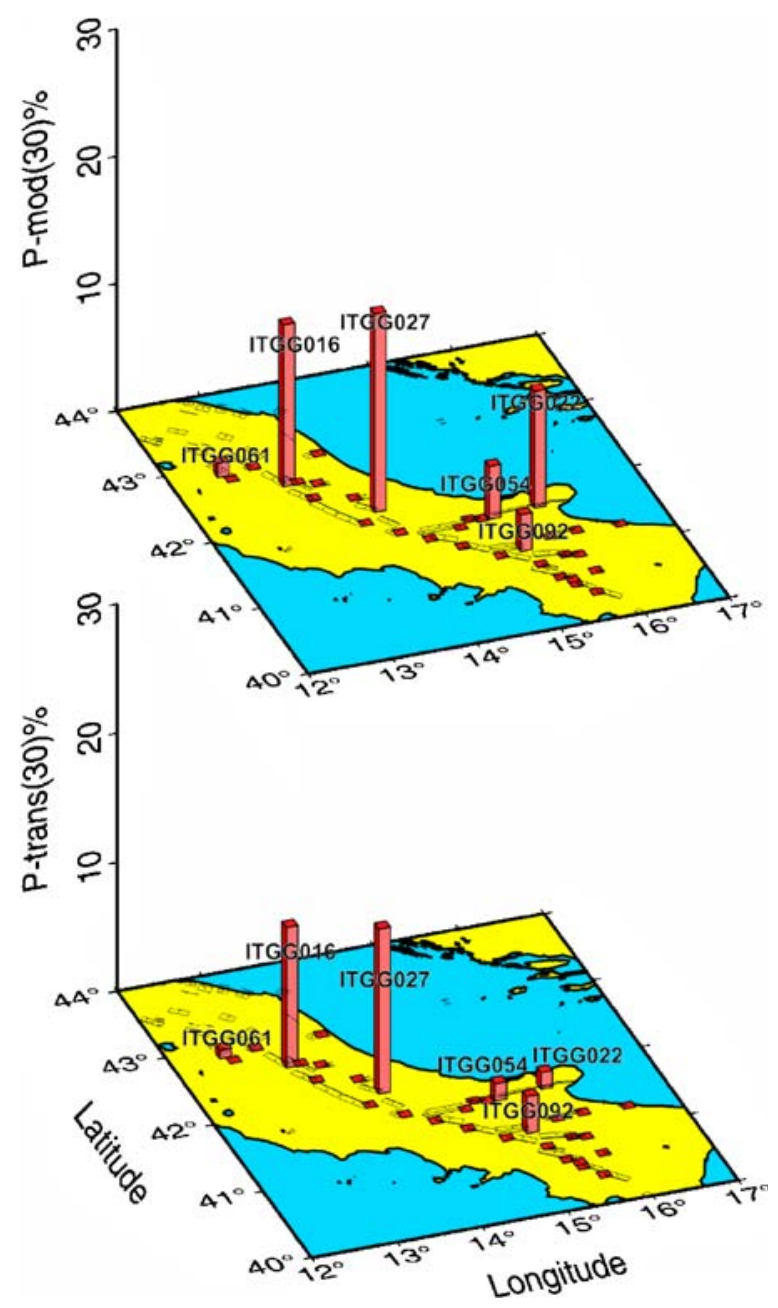

Fig. 4 Maps showing the conditional occurrence probabilities obtained for a characteristic earthquake in the next 30 years starting in January 1, 2007 for the 32 seismogenic sources considered in this study. top Probabilities obtained from the permanent effect only. bottom Probabilities obtained from the sum of the permanent and transient effects

been plotted on a map of seismogenetic sources. The top panel shows the probabilities obtained from the permanent effect only. The bottom panel shows the probabilities obtained from the sum of the permanent and transient effects.

The higher probability is related to Norcia Basin (10.9\%) and Sulmona Basin (12.8\%). The last characteristic events have occurred on these two sources on January 14, 1703 and December 3, 1315 , respectively (Table 1 ).

\section{Conclusions}

We have applied an algorithm modelling the permanent and transient effects of the stress interaction among faults to 32 seismogenic faults of the Southern Apennines in Italy, which are described in the DISS 3.0.2 database.

The first important conclusion that can be drawn from our study is that the renewal model predicts negligible probabilities of failure of these faults for the next 30 years, except for a few of them. This result is easily explained by the fact that the time elapsed since the latest characteristic earthquake is shorter than the estimated recurrence time for most of the sources examined in this study.

The permanent effect of the stress change affects the conditional probability obtained from the unperturbed model in different ways: For some of them, the probability is significantly increased, while for a few others, it is decreased.

The transient effect, modeling a sort of aftershock rate decay, has a minor role after more than 5 years since the latest event reported in the database, the San Giuliano di Puglia, 2002 earthquake.

We conclude that the application of a timedependent renewal model and the inclusion of stress change effects on the earthquake probability computations may significantly affect the results. The quality of the input data necessary for the estimate of the time-dependent earthquake hazard, such as the mean return time and the coefficient of variation of the BPT model, is a critical factor for the reliability of such estimates. This circumstance, and the rareness of strong earthquakes in the study area, that makes it nearly practically impossible to validate renewal models, does not allow to draw results that can be reliably adopted in substitution of the time-independent Poisson hypothesis based on the Gutenberg-Richter relationship (Console et al. 2008).

The analysis developed in the frame of S2 project and used in this work are publicly available (http://legacy.ingv.it/progettiSV/).

Acknowledgements We thank the editors Laura Peruzza and David Perkins, Eleftheria Papadimitriou and another anonymous reviewer for their useful comments that 
contributed to a significant improvement of the article. This work was partially supported for the years 2005-2007 by the Project S2-Assessing the seismogenic potential and the probability of strong earthquakes in Italy (Slejko and Valensise coord.) - S2 Project has benefited from funding provided by the Italian Presidenza del Consiglio dei Ministri-Dipartimento della Protezione Civile (DPC). Scientific papers funded by DPC do not represent its official opinion and policies. The GMT system (Wessel and Smith 1998) was used to plot Fig. 4.

\section{References}

Basili R, Valensise G, Vannoli P, Burrato P, Fracassi U, Mariano S, Tiberti MM, Boschi E (2008) The Database of Individual Seismogenic Sources (DISS), version 3: summarizing 20 years of research on Italy's earthquake geology. Tectonophysics 453:20-43. doi: 10.1016/j.tecto.2007.04.014

Bird P (1999) Thin-plate and thin-shell finite-element programs for forward dynamic modeling of plate deformation and faulting. Comput Geosci 25:383-394. doi:10.1016/S0098-3004(98)00142-3

Chiarabba C, Jovane L, Di Stefano R (2005) A new view of Italian seismicity using 20 years of instrumental recordings. Tectonophysics 395(3-4):251268. http://legacy.ingv.it/CSI. doi:10.1016/j.tecto.2004. 09.013

Console R, Murru M, Falcone G, Catalli F (2008) Stress interaction effect on the occurrence probability of characteristic earthquakes in Central Apennines. J Geophys Res 113:B08313. doi:10.1029/2007JB005418

CPTI04 (2004) Catalogo Parametrico dei Terremoti Italiani. http://emidius.mi.ingv.it/CPTI04/

Dieterich JH (1994) A constitutive law for rate of earthquake production and its application to earthquake clustering. J Geophys Res 99:2601-2618. doi:10. 1029/93JB02581

DISS Working Group (2006) Database of Individual Seismogenic Sources (DISS), Version 3.0.2: a compilation of potential sources for earthquakes larger than $\mathrm{M}$ 5.5 in Italy and surrounding areas. http://www.ingv. it/DISS/, (C) INGV 2005, 2006, Istituto Nazionale di Geofisica e Vulcanologia.

King GCP, Stein RS, Lin J (1994) Static stress changes and the triggering of earthquakes. Bull Seismol Soc Am 84:935-953.

Matthews MV, Ellsworth WL, Reasenberg PA (2002) A Brownian model for recurrent earthquakes. Bull Seismol Soc Am 92:2233-2250. doi:10.1785/0120010267

Mc Cann WR, Nishenko SP, Sykes LR, Krause J (1979) Seismic gaps and plate tectonics: seismic potential for major boundaries. Pure Appl Geophys 117:1082-1147. doi:10.1007/BF00876211

Parsons T (2004) Recalculated probability of $M \geq 7$ earthquakes beneath the Sea of Marmara, Turkey. J Geophys Res 109:B05304. doi:10.1029/2003JB002667

Parsons T (2005) Significance of stress transfer in timedependent earthquake probability calculations. J Geophys Res 110:B05S02. doi:10.1029/2004JB003190

Peruzza L (2007) Note descrittive sui tempi di ricorrenza e probabilità di terremoto caratteristico nei prossimi 30 anni (dal 2007) associata alle GGsources del DISS v. 3.0.2, In OGS (ed.) Rapporti esterni: 2007/33-OGA 11 RISK, Sgonico, OGS, p. 14.

Shimazaki K, Nakata T (1980) Seismic gap hypothesis: ten years later. Geophys Res Lett 7:279-282. doi:10. 1029/GL007i004p00279

Stein R, Barka A, Dieterich J (1997) Progressive failure on the North Anatolian fault since 1939 by earthquake stress triggering. Geophys J Int 128:594-604. doi:10. 1111/j.1365-246X.1997.tb05321.x

Toda S, Stein R, Reasenberg P, Dieterich J, Yoshida A (1998) Stress transferred by the $1995 \mathrm{Mw}=6.9$ Kobe, Japan, shock: Effect on aftershocks and future earthquake probabilities. J Geophys Res 103(B10):24,54324,565. doi:10.1029/98JB00765

Wessel P, Smith WHF (1998) New improved version of the Generic Mapping Tools released. Eos Trans AGU 79:579. doi:10.1029/98EO00426

Zöller G, Hainzl S (2007) Recurrence time distributions of large earthquakes in a stochastic model for coupled fault systems: the role of fault interaction. Bull Seismol Soc Am 97(5):1679-1687. doi:10.1785/0120060262 